\title{
Planning and Developing Courses in Distance Learning Environments: a training course for HiEdTec Project
}

\author{
Joana, Neto* \\ Distance Learning Unit, University of \\ Coimbra \\ joana.neto@uc.pt \\ Sílvia, Nolan \\ Distance Learning Unit, University of \\ Coimbra \\ snolan@uc.pt
}

\author{
António, Mendes* \\ Depart. Informatics Engineering, \\ CISUC and Distance Learning Unit, \\ University of Coimbra \\ toze@dei.uc.pt
}

\begin{abstract}
${ }^{*}$ The adoption of active and technology-enriched methodologies is a widespread reality worldwide in higher education. Didactic models based on active methods prove to be effective in promoting students' learning and are emerging in the context of the professional development of university teachers. Teacher training is fundamental for the promotion of innovative and effective teaching practices and didactic models in the teaching-learning process.

This article aims to describe the instructional designing, developing and executing of a distance learning course, developed within the scope of the HiEdTec Project, for teachers from Middle Asia universities. This is a descriptive article focusing on one of the project's outputs - a distance learning course.
\end{abstract}

\section{CCS CONCEPTS}

- Applied computing; • Education; • Distance learning;

\section{KEYWORDS}

HiEdTec Project, Distance Learning Environments, Instructional design, Higher education

\section{ACM Reference Format:}

Joana, Neto*, Sílvia, Nolan, and António, Mendes. 2021. Planning and Developing Courses in Distance Learning Environments: a training course for HiEdTec Project. In International Conference on Computer Systems and Technologies '21 (CompSysTech '21), June 18, 19, 2021, Ruse, Bulgaria. ACM, New York, NY, USA, 6 pages. https://doi.org/10.1145/3472410.3472440

\section{INTRODUCTION}

"Modernization of Higher education in Central Asia through New Technologies" (HiEdTec) is a project developed under the Erasmus + Programme (KA2 - Cooperation for innovation and the exchange of good practices. Capacity Building in Higher Education), coordinated by the University of Ruse (Bulgaria), and its main aims are to "adapt the education system in the Partner Countries to the digital generation through the introduction and effective implementation of ICT-based innovative educational technologies and

*Place the footnote text for the author (if applicable) here.

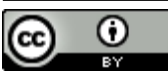

This work is licensed under a Creative Commons Attribution International 4.0 License.

CompSysTech '21, June 18, 19, 2021, Ruse, Bulgaria

(c) 2021 Copyright held by the owner/author(s)

ACM ISBN 978-1-4503-8982-2/21/06

https://doi.org/10.1145/3472410.3472440 didactic models in the teaching process; and to enhance the international dimension of education and training through strengthened links between the European Union (EU) and Partner Countries (PC) universities, exchange of expertise and good practices in the areas of digital pedagogies and IET" [1].

The partner countries are Turkmenistan, Tajikistan, Uzbekistan, Kyrgyzstan, Kazakhstan and the program countries are Bulgaria, Italy, Portugal and Luxembourg. It is expected that the project will "help to turn partner universities into innovative universities and to improve the quality of the trained specialists, who are necessary to perform the Digital Transformation of Industries (Industry 4.0). It is also desired that the project products will be of benefit for all stakeholders in education, such as national and university policy-makers in the field of education; university academics who are trainers / lecturers / learners; scientific, economic and social partners" [1].

The University of Coimbra is one of the Program institutions in HiEdTec and it is represented by its Distance Learning Unit (UC_D). UC_D was responsible for: compiling a syllabus of a course for the acquisition of digital skills and innovative teaching and learning methods, namely to design, develop and implement online courses; and for developing the second part of the Handbook of Innovative Educational Technologies [2] which turned out to be a valuable resource to support the online training.

To achieve the project goals and fulfill the tasks planned, 600 trainers needed to be trained. Taking advantage of the fourth project meeting that was to take place in Portugal one representative of each PCs university would be trained. After that each of these trainers would train 4 more trainers at their higher education institutions for the acquisition of digital skills and innovative teaching and learning methods. At each PC University the trainers would then organize and conduct courses for lecturers on this same topic. The courses would be organized and have the support of the respective university governance. The target was to train 40 lecturers at each PC University.

It was in this context that the need to design and develop a training course Planning and Developing Courses in Distance Learning Environments course emerged. The first design developed for this course considered a face-to face approach, as it should take place in a project meeting where for 3 days 20 trainees would work together. Because of the Covid-19 pandemic all the face-to-face activities were cancelled, and the course was redesigned considering a distance learning format.

Therefore, we designed a 40-hour e-learning course, in which trainees would have to work 2 hours a day to achieve the main course goals. The course ran asynchronously between the $21^{\text {st }}$ of 
April and the $31^{\text {st }}$ of May 2020. The University of Coimbra's Moodle platform was used to deliver the course.

Considering the new format, it was decided to include 5 participants per institution, making a total of 75 trainees.

The Planning and Developing Courses in Distance Learning Environments course aimed to be a contribution to achieve an innovative approach to Higher Education and intended to present a general overview on planning and development of courses in distance learning environments.

\section{BACKGROUND}

\subsection{Instructional design}

Instructional design is a central issue in e-learning, enabling instruction to be more effective, efficient and reliable. The instructional design process considers all aspects and elements of the learning environment, following organized procedures that provide guidance for teachers and students, enhancing the relationship between the instructor (teacher), the learners, the contents, and the technology [2]. It aims to identify the setting for instruction, which will enhance learning, retention and learning transfer [3].

The instructional design concept is currently based on constructivist theories, and the main issue is placed on how successful learning can be developed by analyzing why learners behave differently, how learners construct meaning from individual experiences, and how they are able to sort situations out, rather than performing automatic practices without understanding how to carry them out.

Although a variety of models, or processes, have been developed, most descriptions include these core elements: analysis, design, development, implementation and evaluation (ADDIE) [4]. These components are able to ensure the necessary consistency among the instructional elements - the instructor (teacher), the learners, the contents, and the technology.

We can establish these main characteristics of instructional design [2]:

- Learner-centered - the learner-centered approach places the participant in the center of the learning experience, encouraging a dynamic relationship between the learners, the instructor (teacher) and the learning material. When the learner is the center of instruction, she/he will be able to build cognitive connections with the contents.

- Goal-oriented - identifying what the learner should know is essential to set the arrival point and is particularly important to check the achievement of the learning goals.

- 3. Focus on real world performance - instructional design should focus on preparing learners to apply knowledge in the real world; it cannot be reduced to recalling information or applying some rules in artificial and basic tasks. For that reason, there should be an analogy between the virtual learning environment and the settings in which the learning will be applied.

- 4. Focuses on measurable outcomes - the instructional design process must also be concerned with the development of valid and reliable assessment tools, capable of assessing learning goals.

- 5. Empirical - data is essential for the success of instructional design. It will tell us what learners already know and what they need to know, and if the applied pedagogical strategies promote effective learning.

- 6. Team effort - because instructional design projects are often complex, they need the collaboration of a specialized team. Usually, it includes a subject matter expert, an instructional designer, administrative support staff, technical support staff (designer and/or engineer).

The design of different types of learning environments can depend on the learning objective, target audience, access (physical, virtual and/or both), and type of content. It is important to know how the learning environment will be used, and the influences of the tools, techniques and technology in learning outcomes achievement. That is why it is so important to have a systematic process conducted by a team of professionals that analyze, design, develop, implement and evaluate suitable pedagogical solutions. The team knows that instructional design should be learner-centered and goal-oriented and must be able to develop reliable and valid instruments and strategies to measure the knowledge learners will apply in the real world.

\subsection{UC_D Instructional design}

The UC_D instructional design has its foundations in the ADDIE model, and its five steps [4] - Analysis, Design, Development, Implementation, Evaluation, can be seen as dynamic and flexible standards to build online courses. We see the ADDIE model as a cyclic and iterative process, where progress from one phase to the next will regulate and determine interventions which may be required and the next steps to be taken. However, the ADDIE model, as others, is seen like a theoretical approach that, many times, is not extended to practice. Despite being aware of the process-based instructional design models, instructional designers usually use a model's guidelines and frameworks, but do not use these models as rigid conceptions [5] and tend to adapt instructional design models. The methodology of instructional design used incorporates and adapts the five phases Analyze, Design, Develop, Implement, and Evaluate; in our iterations the evaluative component is present throughout the formative cycle, acting as feedback from the other stages [2].

2.2.1 Who is involved. Creating online courses involves a different set of skills and knowledge from delivering content in a traditional course setting [6]. The instructional design of a course creates learning environments and experiences that enhance learning [7]. In online courses, designing and teaching are variables strongly connected, so it is important that instructional designers and teachers can work together throughout the course development. Teachers are scientific specialists responsible for content development; instructional designers are the pedagogical experts, who support teachers throughout the process. Many authors agree that an elearning project should be developed by a multidisciplinary team, in which content specialists, technicians, designers, and others can join their expertise in a suitable and constructive manner [8].

At the University of Coimbra, distance-learning courses are developed by a joint work strategy between the teachers and the Distance Learning Unit (UC_D), thus combining scientific and pedagogical knowledge in the field of distance learning environments 
and scenarios. There is a multidisciplinary team specialized in Educational Sciences, Design and Multimedia and Informatics working together with professors and lecturers to design, develop, implement and evaluate in an action research context.

\section{PLANNING AND DEVELOPING COURSES IN DISTANCE LEARNING ENVIRONMENTS COURSE}

As previously referred the Planning and Developing Courses in Distance Learning Environments course as presented emerged from an urgent need brought on by the Covid-19 pandemic situation we live. We had little time to prepare it as an e-learning course, so we used one of the HiEdTec Project outputs - the Handbook of Innovative Educational Technologies (part two) [2], that was written by the course instructors, to support the content development. After the instructional principles, plans, templates or layouts, agents (learners and instructors) and resources were set, we moved forward to determine how the course materials' features could be connected and organized in the learning platform. We defined that mostly texts, images and schemes for contents presentation would be used and we also defined a specific forum for interaction and communication in each module.

\subsection{Learning outcomes}

By the end of the course, trainees were expected to have develop general skills for planning educational content in distance learning environments, such as:

Characterize learning environments in distance learning education.

Recognize Moodle as a Learning Management Platform.

Describe pedagogical models of distance courses.

Identify basic concepts of curriculum planning in distance learning education.

Apply the main steps of instructional design.

Apply basic concepts about curriculum planning in distance learning education.

Select the basic Moodle tools and resources.

Apply the basic Moodle tools and resources.

Plan a learning scenario on the Moodle platform.

\subsection{Methodology}

Planning and Developing Courses in Distance Learning Environments was planned with a sequential structure organized in 7 thematic modules. The focus of the online course was the acquisition of theoretical concepts, with immediate application of knowledge through activities that allowed the systematization of learning.

Each module had its own timetable, suggesting that the trainee dedicate 2 hours of daily work to the course. Each thematic module had supporting texts, written within the scope of the Handbook of Innovative Educational Technologies (part two), by the course instructors. At the end of each module, complementary literature was recommended, so that learners could deepen their knowledge.

The course methodology was based on learners' active learning, with the monitoring of instructors. The theoretical concepts were presented and discussed with the group, and learners had the opportunity, through activities, to reflect on how to apply the content to their professional context.

Learning approaches:

Lectures / Presentations - for theoretical explanations and key concepts.

Individual and group reflections - thinking and reflecting about learners' professional experiences related to the course topics.

Practical use - learners were guided to apply the theoretical concepts in a practical exercise on planning.

The instructional design developed for the training considers flexibility, but also the commitment of trainees. The teaching process was based on the systematic monitoring of the learners' work, namely in the study of the contents, clarification of doubts and in the accomplishment of learning activities. The instructors closely monitored and supported learning, by motivating and engaging trainees.

Group activities were planned to allow trainees to develop videolectures on course contents.

The access to the platform was flexible, allowing learners to organize and adjust their working hours according to their availability to manage the activities proposed.

\subsection{Syllabus and Structure}

Planning and Developing Courses in Distance Learning Environments is a course about general concepts of planning and development of distance learning units and contents. The syllabus was organized into 7 modules:

Distance learning environments.

Planning and instructional design in distance learning environments.

A pedagogical model of distance learning: UC_D.

Learning management systems: the Moodle platform.

Learning objects and contents: pedagogical development.

Learning assessment.

Planning my distance learning scenarios.

It is a course with a sequential and modular structure, and each module had its own timetable. In the course's main page, several areas were established (figure. 1):

General information and Course overview, to give learner's the framework of the course; this included a presentation video with the course instructors to introduce the course and welcome trainees.

Specific areas to support the organization of study time and assist in monitoring learning, like the Schedule (where the main dates of the course were presented - start and end dates of each module, start and end dates of each activity), Tasks (page with the course activities table).

General forum (general communication area of the course; it was a forum for general information and clarification of academic and pedagogical issues).

Each module was designed with a particular structure, presenting important pedagogical information to facilitate the learner's autonomy on the platform. A brief description of the module, its learning outcomes and a roadmap were always provided. The module's structure consisted of a content area in which contents were 


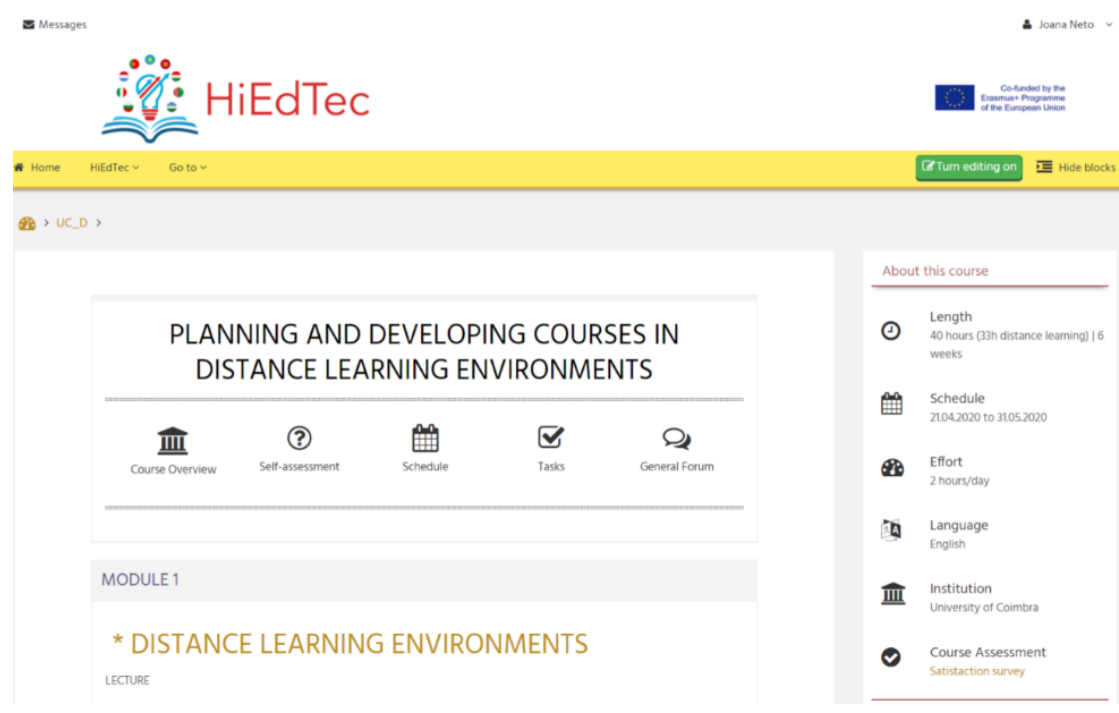

Figure 1: Main page of the course
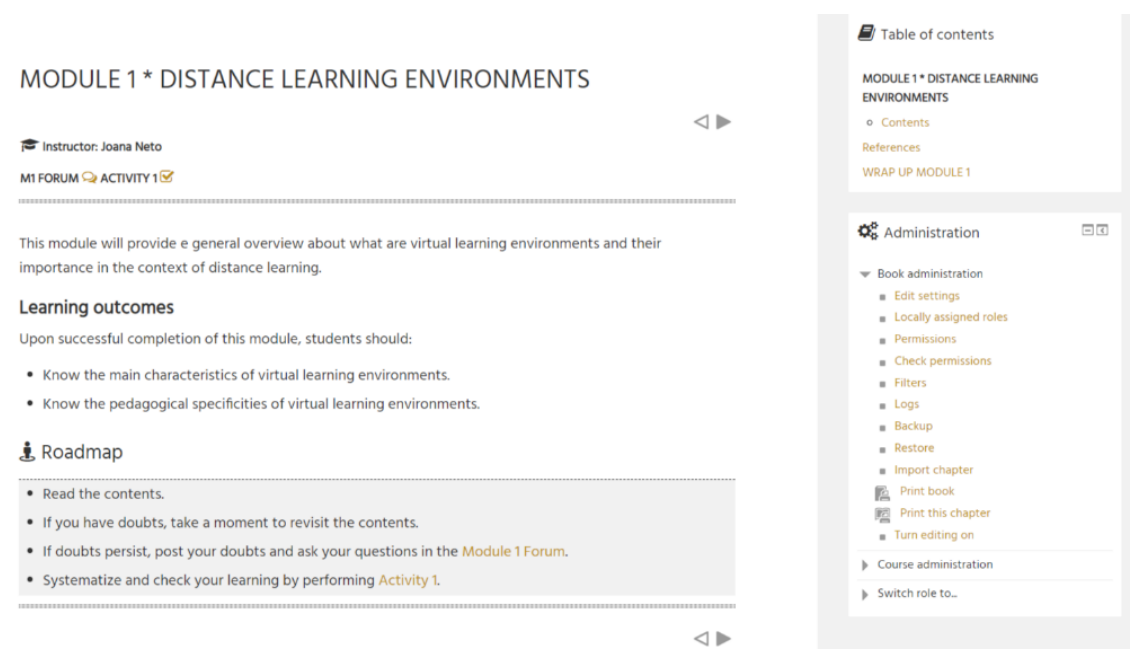

Figure 2: Module 1 entry page

presented, an area for bibliographic references for further consultation, and a wrap-up section. The wrap-up section contained a brief summary of the main points covered, and some questions that could be taken into consideration for a guided reflection about learning (figure. 2).

The contents combined images and text, but the excessive use of images onscreen was avoided. Different strategies were used to provide contents in an organized but non-disruptive manner. So, whenever it was necessary to provide additional information, we used drop-down boxes that only opened when the trainee chose to see it. Contents were embedded in the platform page, but were also available for downloading (figure. 3).

\section{COMMUNICATION AND INTERACTION}

The interaction and communication in Planning and Developing Courses in Distance Learning Environments course was established asynchronously, not requiring participants' simultaneous presence on the platform.

The communication tools used during the course were the forums and the private messaging system of the Moodle platform. A general forum was used to post notices and / or important messages for all participants of the course. The general forum was free to be used by any participant in the course.

A forum was also designed for each module, aiming at clarifying doubts regarding the module's contents. This option of having a forum for each module was based on the advantage of better directing the interventions and communication related to the contents. 
Table 1: Completion rates

\begin{tabular}{ll}
\hline Trainees & Data \\
Trainees enrolled in the course & 76 \\
Trainees who accessed the course & 74 \\
Trainees who have successfully completed all course activities & 46 \\
\hline
\end{tabular}

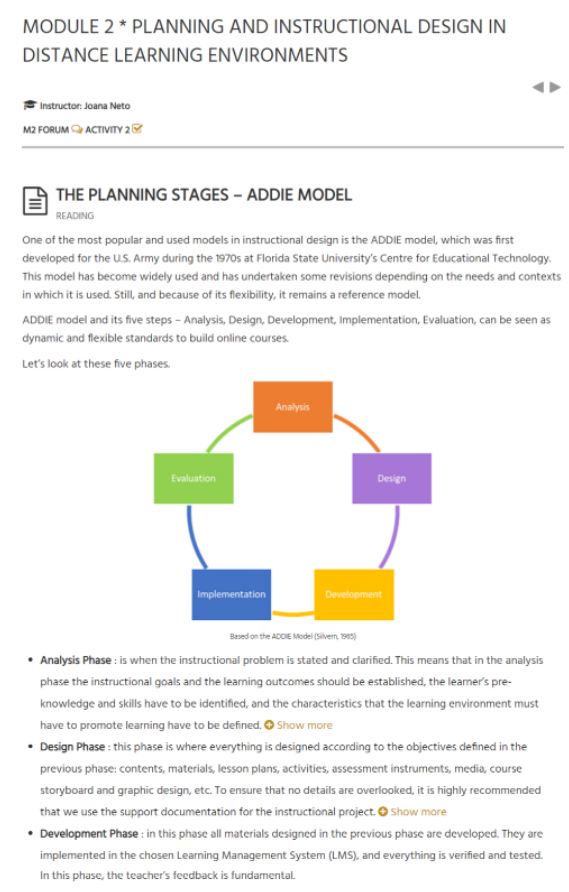

Figure 3: Module 2-page contents

\section{ASSESSMENT}

The trainees' evaluation was formative and continuous, based on the activities that were requested throughout the course.

At the beginning of the course, learners had to answer a selfassessment questionnaire about the general themes of the course, to help them to situate their knowledge and engage them with the course materials.

During the course we proposed one learning activity per module. The activities were all mandatary and intended to promote the achievement of the module's goals.

In all modules, trainees were requested to develop video-lectures related to the module contents. Those video-lectures intended to be used in future training activities, where the trainees will act as trainers.

The activities were carried out in groups, each corresponding to one partner institution. This enabled us to promote collaborative learning and to have participants working in their own context, given the fact that, as said, they would become trainers themselves in their institutions (figure. 4).

The feedback mechanisms became effective through general comments from the instructors in forums, and through specific comments, inputs and suggestions in the area where activities

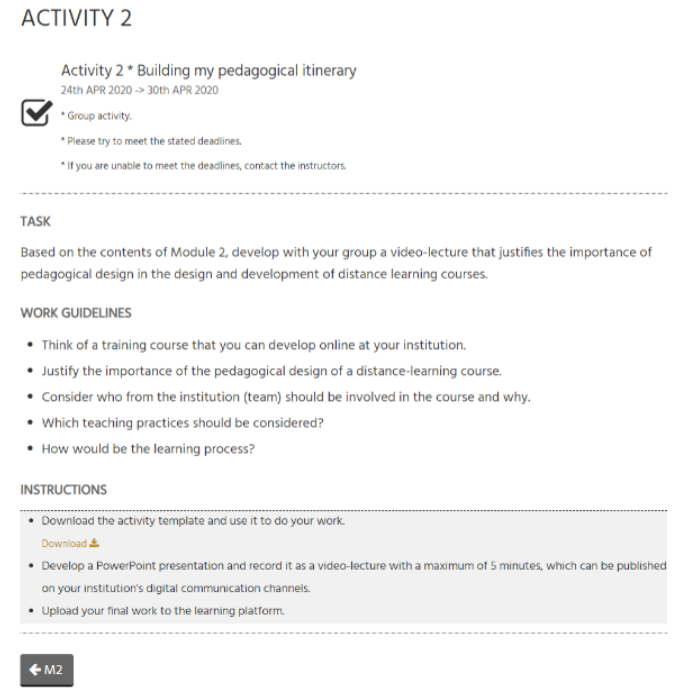

Figure 4: Course activity $n .^{\circ} 2$

were graded. Whenever it was necessary, groups were advised to reformulate the work. Overall, trainees were compliant with the tasks they were given, and we saw improvements from one module to the next, seeing that they took into consideration the feedback provided. However, improvements were not sufficient to say that participants were able to go from theory to practice, as they focused their work more on the concepts and theory.

At the end of the course, we had the data indicated in Table 1:

In addition to the trainee's evaluation, for certification purposes, we also evaluated the course, measuring trainee satisfaction.

We administered a questionnaire consisting of 21 questions. In addition to the collection of sociodemographic data, the opinion of the participants was assessed regarding the usability of the platform, and the relevance and quality of the contents and resources. The role and performance of instructors, and interpersonal communications and interactions were also analyzed. Other issues related to the expectations, strengths and weaknesses of the course were also discussed.

Despite having obtained few responses, the results were quite satisfactory.

\section{CONCLUSION}

This article describes the design and development of the distancelearning course - Planning and Developing Courses in Distance Learning Environments, that emerged in the context of an international project. 
The course's instructional design was based on the pedagogical model of the Distance Learning Unit of the University of Coimbra (UC_D), whose methodology incorporates and adapts the ADDIE model and combines scientific and pedagogical knowledge in the field of distance learning environments and scenarios.

UC_D applied a holistic approach that integrates cognitive and constructivist foundations, where the content and its delivery are important, as well as the way the learner will be engaged with the content and will apply and transfer knowledge. In addition, the course's instructional design and the approach to teaching and learning strategies had constructivist foundations, making sure that the learner had an active role in the construction of his knowledge. Also, the teaching methodologies and the course structure and organization were designed to promote learner engagement.

The assignments developed reflected more the theoretical component of the concepts covered during the course than their practical application, as intended.

With regard to interaction and exchange of ideas, either among the trainees or between the trainees and the trainers, the intended interaction was not as expected. The inputs/ideas that the trainers suggested for reorganizing and/or improving the assignments were not taken into consideration, contrary to what was expected; the forums, and despite the challenges launched, were little participated, and the group limited itself to doing only the activities involved in course evaluation strategies.

The HiEdTec project presents itself as an important contribution to the promotion and development of active teaching-learning methodologies in Middle Asian countries. We hope to keep continuous contributions for similar projects.

\section{ACKNOWLEDGMENTS}

The authors would like to thank all the HiEdTec partners, and especially to the Project Coordinators at the University of Ruse. We would also like to acknowledge all the participants of the online course described in this paper. This initiative was also possible due to the co-financing and support of the Erasmus+ Programme.

\section{REFERENCES}

[1] HiEdTec. Modernization of Higher Education in Central Asia through New Technologies. Retrieved from https://hiedtec.ecs.uni-ruse.bg/?cmd=gsIndex

[2] Neto, J., Nolan, S., (2020). Handbook of Innovative Educational Technologies (part two). [Under the general editing of António Mendes]. With the support of the Erasmus+ Programme of the European Union. ISBN 978-954-712-787-6. Available at https://hiedtec.ecs.uni-ruse.bg/index.php? $\mathrm{cmd}=\mathrm{cmsPage} \& \mathrm{pid}=38$.

[3] Gagné, R. and Briggs, L.J. (1974) Principles of Instructional Design. Holton, Rinehart \& Winston, New York.

[4] Silvern, L.C. (1965). Basic Analysis. Los Angeles: Education and Training Consultants.

[5] Kenny, R., Zhang, Z., Schwier, R., \& Campbell, K. (2005). A review of what instructional designers do: Questions answered and questions not asked. Canadian Journal of Learning and Technology/La revue Canadienne de L' apprentissage et de la Technologie, 31(1). Retrieved from http://cjlt.csj.ualberta.ca/index.php/cjlt/ article/view/147/140

[6] Miller, J. L. (2007). The new education professionals: The emerging specialties of instructional designer and learning manager. International Journal of Public Administration, 30(5), 483-498. doi:10.1080/01900690701205970

[7] Merrill, M. D., Drake, L., Lacy, M. J., \& Pratt, J. (1996). Reclaiming instructional design. Educational Technology, 36(5), 5-7. Retrieved from http://mdavidmerrill. com/Papers/Reclaiming.PDF

[8] Fernandez. M., C., \& Montes de Oca, M., (2003). Aspectos a garantizar en la confeccion de cursos virtuales. Congreso Virtual Latinoamericano de Educación a Distancia LatinEduca2004.com. Retrieved March 27, 2008 from: http://www. ateneonline.net/datos/35_01_Fernandez_Montoto_Carmen.pdf 